\title{
Desenvolvimento de biocompósitos fúngicos utilizando resíduos industriais
}

\author{
Fungal biocomposites development \\ from industrial waste
}

\author{
Maria Isabel Rocha ${ }^{1}$, Sara Benkendorf ${ }^{2}$, \\ Regina Maria Miranda Gern ${ }^{3}$, Josiane Costa Riani ${ }^{4}$, Elisabeth Wisbeck ${ }^{1}$
}

\author{
${ }^{1}$ Programa de Pós-Graduação em Engenharia de Processos, Universidade da Região de Joinville, UNIVILLE Rua Paulo \\ Malschitzki, 10, CEP: 89219-710, Joinville, SC, Brasil \\ ${ }^{2}$ Departamento de Engenharia Química, Universidade da Região de Joinville, UNIVILLE, Rua Paulo Malschitzki, 10, \\ CEP: 89219-710, Joinville, SC, Brasil \\ ${ }^{3}$ Programa de Pós-Graduação em Saúde e Meio Ambiente, Universidade da Região de Joinville, UNIVILLE Rua Paulo \\ Malschitzki, 10, CEP: 89219-710, Joinville, SC, Brasil \\ ${ }^{4}$ Departamento de Engenharia Mecânica, Universidade da Região de Joinville - UNIVILLE_Rua Paulo
}

Malschitzki, 10, CEP: 89219-710, Joinville, SC, Brasil

e-mail: isabelrocha@outlook.com, elisabeth.wisbeck@univille.br, sarabenkendorf@hotmail.com,regi-

na.maria@univille.br, josiane.riani@univille.br

\section{RESUMO}

O processo de fabricação de alimentos produz grande quantidade de resíduos orgânicos. Uma indústria de extração de aromas, por exemplo, pode gerar, anualmente, 104 e 92 toneladas de resíduo de erva-mate e guaraná, respectivamente. Uma alternativa para o reaproveitamento desse material lignocelulósico seria utilizálos na produção de biocompósitos com micélio fúngico atuando como ligante das partículas do substrato. Sendo assim, objetivou-se nesse trabalho a produção de biocompósitos a partir de Pleurotus sajor-caju utilizando os resíduos de erva-mate e guaraná na proporção $(1: 1)(\mathrm{m} / \mathrm{m})$, verificando a influência da fração de inóculo 10,20 e $30 \%$ e da temperatura de secagem de 40 e $60^{\circ} \mathrm{C}$. Para cada condição testada foi avaliado o tempo de crescimento micelial, o teor de umidade inicial, a velocidade inicial de secagem, a resistência à compressão, absorção de umidade do ar e absorção de água. A condição determinada foi a de $10 \%$ de inóculo e secagem a $60^{\circ} \mathrm{C}$, pois apresentou maior resistência à compressão $(0,094 \mathrm{MPa})$, menor absorção de água (91\%), maior velocidade de secagem $(27,7 \mathrm{~g} / \mathrm{dia})$. Os biocompósitos utilizam o crescimento biológico e não processos de fabricação com intenso desperdício de energia, ainda exigem apenas resíduos orgânicos de baixo custo como matéria-prima, podendo preencher geometrias complexas apresentando potencial para a confecção de embalagens, pois são materiais seguros que apresentaram boa resistência a compressão e baixa absorção de umidade do ar e de água.

Palavras-chave: Pleurotus sajor-caju, resíduos industriais, cultivo sólido, biocompósitos.

\section{ABSTRACT}

The food manufacturing generates a large amount of organic waste. A flavor industry, for example, can generate annually 104 and 92 tonnes of mate and guarana residues, respectively. An alternative to the reuse of this lignocellulosic material would be to use them in the production of biocomposites with fungal mycelium acting as a binder of the substrate particles. Therefore, the objective of this work was to produce fungal biocomposites of Pleurotus sajor-caju using the mate and guarana residues in a ratio of $(1: 1)(\mathrm{w} / \mathrm{w})$, checking the influence of the 10, 20 and $30 \%$ inoculum fraction and the drying temperature of $40^{\circ} \mathrm{C}$ and $60^{\circ} \mathrm{C}$. For each condition tested, mycelial growth time, initial moisture content, initial drying rate, compressive strength, air moisture absorption and water uptake were evaluated. The condition determined to produce the biocomposites was $10 \%$ of inoculum and drying at $60^{\circ} \mathrm{C}$, as it presented higher resistance to compression $(0.094$ $\mathrm{MPa})$, lower absorption of water $(91 \%)$, higher drying rate $(27.7 \mathrm{~g} /$ day). The biocomposites utilise biological growth rather than expensive energy intensive manufacturing processes and require only low-cost organic 
waste as feedstock, can grow to fill complex geometries presented potential for packaging, as they are safe materials that have good compressive strength and low water absorption.

Keywords: Pleurotus sajor-caju, industrial residues, solid culture, biocomposites.

\section{INTRODUÇ̃̃O}

Como consequência do expressivo destaque da atividade industrial de produção de alimentos há uma maior demanda na extração de matérias-primas, processamento, produção, distribuição e geração de resíduos para tratamento e destinação. Uma indústria de extração de aromas, por exemplo, pode gerar, anualmente, 104 e 92 toneladas de resíduo de erva-mate e guaraná, respectivamente, após seu processo de extração.

Uma alternativa para o aproveitamento dos resíduos dessas atividades industriais seria sua utilização na produção de biocompósitos fúngicos [1]. A produção deste compósito fúngico consiste basicamente em, inocular os resíduos (substrato) com uma espécie fúngica previamente selecionada dentro de uma moldeira e esperar alguns dias até a completa colonização deste substrato pelo micélio fúngico. $\mathrm{O}$ crescimento micelial em torno do resíduo permite a formação do biocompósito, que adquire o formato do recipiente onde este foi cultivado. O material é então desmoldado e desidratado para cessar o crescimento fúngico [2]. Os biocompósitos baseados em materiais naturais são uma das áreas emergentes na ciência de polímeros [3]. $\mathrm{O}$ aumento de estudos desses materiais se dá principalmente por serem materiais biodegradáveis e assim possuírem a possibilidade de compostagem sendo no final de seu ciclo de vida, devolvidos ao solo, transformando-se em nutrientes, oferecendo uma alternativa sustentável ao uso de plásticos à base de petróleo [4]. A empresa Ecovative [5], por exemplo, comercializa produtos estruturais como o Myco Board que se assemelha à madeira e o Myсо Foam para substituição de embalagens de poliestireno expandido, utilizando resíduos agroindustriais.

Os fungos do gênero Pleurotus, juntamente com outros fungos, formam um grupo denominado de "fungos de podridão branca", por produzirem um micélio branco e degradarem tanto a lignina como a celulose. Para tanto, possuem um complexo enzimático lignocelulotítico único com enzimas como celulase, ligninase, celobiase, lacase e hemicelulase que fazem com que estes fungos degradem uma grande variedade de resíduos lignocelulósicos [6].

Assim, o objetivo deste trabalho foi desenvolver biocompósitos fúngicos a partir de resíduos da indústria de aromas erva-mate e guaraná e micélio de Pleurotus sajor-caju com propriedades mecânicas satisfatórias para serem utilizados em embalagens oferecendo uma alternativa sustentável ao uso de plásticos à base de petróleo.

\section{MATERIAIS E MÉTODOS}

\subsection{Micro-organismo e manutenção}

A espécie Pleurotus sajor-caju utilizada foi obtida da Coleção de Culturas de Basidiomicetos do Instituto de Botânica (São Paulo/SP) sob o código CCB 019. A linhagem foi mantida em placas de Petri contendo o meio TDA (trigo, dextrose e ágar) [7]. Segundo ZIEGLER et al. [4] a utilização de fungos antibacterianos pode conferir esta propriedade para o material biocompósito.

\subsection{Inóculo}

Para o inóculo foram utilizados grãos de trigo lavados em água corrente e cozidos durante 10 minutos em água destilada na proporção 1:2 (grãos de trigo: água - p/v). O extrato proveniente do cozimento foi drenado e os grãos adicionados de $\mathrm{CaCO}_{3}$ e $\mathrm{CaSO}_{4}$ nas proporções de $0,35 \%$ e 1,3\%, respectivamente, em relação a massa dos grãos antes da fervura. Os grãos foram, então, embalados (250g de grãos de trigo/pacote de polipropileno) e esterilizados a $121^{\circ} \mathrm{C}$, durante 1 hora. Após, cada pacote foi inoculado com 3 discos de ágar de $12 \mathrm{~mm}$ de diâmetro contendo o micélio fúngico de $P$. sajor-caju CCB 019 e incubado a $28^{\circ} \mathrm{C}$, na ausência de luz, até colonização total dos grãos de trigo [8].

\subsection{Preparo e secagem dos biocompósitos}

Os resíduos de erva-mate e guaraná na proporção $(1: 1)(\mathrm{m} / \mathrm{m})$, mostrados na Figura 1 , foram obtidos logo após o processo de extração de aromas por uma indústria alimentícia e aqui são chamados de substrato. $\mathrm{O}$ substrato foi colocado em saco ráfia, imerso em água por 12 horas e escorrido por cerca de 2 horas [9]. 
Com a finalidade de suplementar o substrato com uma fonte de nitrogênio, foi adicionado $5 \%$ de farelo de arroz e embalado em pacotes de polipropileno $28 \mathrm{x} 40 \mathrm{~cm}$ e esterilizados a $121^{\circ} \mathrm{C}$ e 1 atm por 1 hora. A quantidade de substrato em cada pacote foi de $150 \mathrm{~g}$ em relação à massa de substrato seco.

A inoculação foi realizada em câmara de fluxo laminar com 10, 20 ou 30\% de inóculo de P. sajorcaju em relação à massa de substrato seco. Foram preparados 4 pacotes de cada substrato para cada fração de inóculo. Os pacotes foram incubados em estufa bacteriológica a $30 \pm 2^{\circ} \mathrm{C}$, na ausência de luz, até a completa colonização do substrato pelo micélio fúngico.

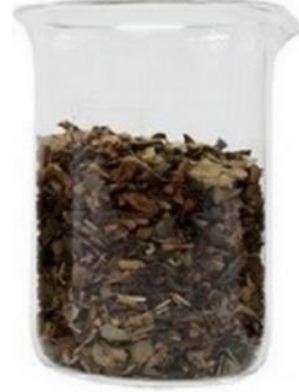

Erva-mate

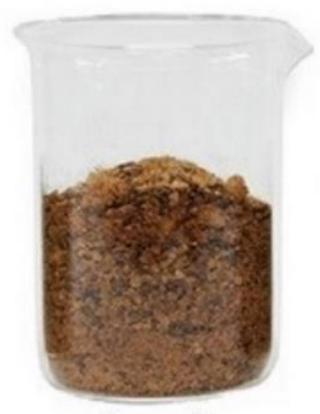

Guaraná

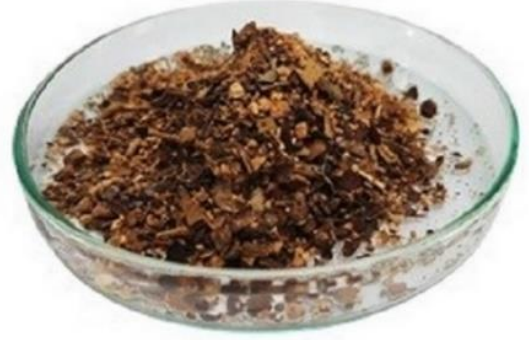

Erva-mate e guaraná (1:1)

Figura 1: Resíduos de erva-mate e guaraná.

Os substratos colonizados foram triturados em processador de alimentos até obter uma mistura homogênea. Em moldes plásticos cilíndricos $(6 \mathrm{~cm} \varnothing)$ foi introduzido $15 \pm 0,5 \mathrm{~g}$ (base seca) de substrato processado, este foi compactado assepticamente, até atingir $2,5 \mathrm{~cm}$ de altura para obter-se os corpos de prova de acordo com a NBR 8082 [10]. Esse procedimento foi realizado em câmara de fluxo laminar. Tanto o processador quanto os moldes sofreram um tratamento asséptico com álcool $70 \%$ e ficaram 15 minutos sob luz UV. Foram confeccionados 24 corpos de prova para cada fração de inóculo. Os moldes foram fechados e incubados em estufa bacteriológica na ausência de luz, a $30 \pm 2^{\circ} \mathrm{C}$, até o restabelecimento das hifas do micélio fúngico (recolonização do substrato).

Após a completa recolonização do substrato, metade dos corpos de prova foram secos em estufa com circulação forçada de ar na temperatura de $40^{\circ} \mathrm{C}$ e a outra metade a $60^{\circ} \mathrm{C}$. A massa inicial $\left(\mathrm{M}_{\mathrm{i}}-\mathrm{g}\right)$ foi anotada e medições de massa foram realizadas a cada 24 horas até obtenção da massa constante $\left(\mathrm{M}_{\mathrm{f}}-\mathrm{g}\right)$. Com estes dados o teor de umidade inicial (U - \%) foi determinado de acordo com a Equação (1) e curvas de secagem (massa x tempo) foram construídas para obter-se a velocidade inicial de secagem (v - g/dia), de cada condição, pela equação da fase linear da curva. Após secagem, os corpos de prova foram desenformados e armazenados em dessecador até serem utilizados nas análises.

$$
U\left(\%=\frac{M_{i}-M_{f}}{M_{i}} * 100\right)
$$

\subsection{Análise dos biocompósitos}

O tempo de crescimento micelial (dias) foi determinado desde a inoculação até a completa colonização do substrato pelo micélio fúngico nos pacotes e o tempo total (dias) desde a inoculação até a completa recolonização do substrato nos moldes.

O teste de resistência à compressão foi realizado em 5 corpos de prova de cada condição em uma máquina universal de ensaios mecânicos (EMIC DL10000/700) de acordo com a NBR 8082 [10]. A tensão de compressão $\left(\sigma_{c}-\mathrm{MPa}\right)$ foi calculada em $10 \%$ de deformação, que representa a deformação máxima permitida para utilizações práticas, por meio da Equação (2), na qual se define a tensão como sendo a razão entre a força de compressão $(\mathrm{F})$ e a área da seção transversal do corpo de prova $\left(\mathrm{A}_{0}\right)$.

$$
\sigma_{c}(M P a)=\frac{F}{A_{0}}
$$

O teste de absorção de umidade do ar (AbsU - \%) foi realizado em 3 corpos de prova de cada condição. Os corpos de prova foram mantidos em temperatura ambiente $\left(21-27^{\circ} \mathrm{C}\right) \mathrm{com}$ a umidade relativa do ar monitorada por um termohigrômetro (INCOTERM) durante 30 dias. Inicialmente $\left(\mathrm{M}_{\mathrm{i}}-\mathrm{g}\right)$ e periodicamen- 
te $\left(\mathrm{M}_{\mathrm{t}}-\mathrm{g}\right)$ as amostras foram pesadas e o teor de absorção de umidade foi calculado de acordo com a Equação (3). Após este período, a fim de avaliar se o tempo de exposição influenciou a resistência à compressão deste material, corpos de prova foram avaliados novamente em relação à resistência à compressão.

$$
\operatorname{Abs} U(\%)=\frac{M_{t}-M_{i}}{M_{i}} * 100
$$

O teste de absorçao de agua (AA - \%) foi realizado em 3 corpos de prova de cada condição com o método de imersão repetida D-570 [11]. Para tanto os corpos de prova tiveram sua massa mensurada, massa inicial $\left(\mathrm{M}_{\mathrm{i}}-\mathrm{g}\right)$ e após foram imersos em água destilada, com $\mathrm{pH} 7 \pm 1$, temperatura de $25 \pm 1{ }^{\circ} \mathrm{C}$, permanecendo cobertos por $25 \pm 5 \mathrm{~mm}$ de água durante 2 e 24 horas. Em cada um dos tempos os corpos de prova foram retirados da água e com auxílio de papel absorvente o excesso de água foi removido. A massa dos corpos de prova após os tempos de imersão $\left(\mathrm{M}_{\mathrm{ti}}-\mathrm{g}\right)$ foi medida para determinar o percentual de absorção de água de acordo com a Equação (4).

$$
A A(\%)=\frac{M_{t i}-M_{i}}{M_{i}} * 100
$$

Utilizou-se a microscopia eletrônica de varredura (MEV) com a finalidade de observar a morfologia da superfície do biocompósito produzido na melhor condição definida neste trabalho. Foram retiradas amostras, próximas de 3 a $5 \mathrm{~mm}$, recobertas com uma camada condutora de ouro aplicando voltagem de aceleração dos elétrons de $5 \mathrm{kV}$ e magnificação das imagens de 25 à 2000 vezes.

A estabilidade térmica do biocompósitos fúngico produzido na melhor condição definida neste trabalho foi investigada pela análise termogravimétrica que realizada em equipamento TGA-Q50 (TA Instruments). A razão de aquecimento foi de $10{ }^{\circ} \mathrm{C} / \mathrm{min}$, partindo de 25 a $600{ }^{\circ} \mathrm{C}$ em atmosfera de nitrogênio (vazão de $60 \mathrm{~mL} / \mathrm{min})$.

Os resultados de teor de umidade inicial $(\mathrm{U}-\%)$, velocidade inicial de secagem ( $\mathrm{v}-\mathrm{g} / \mathrm{dia})$, tensão de compressão $\left(\sigma_{\mathrm{c}}-\mathrm{MPa}\right)$, absorção de umidade do ar (AbsU - \%) e absorção de água (AA - \%) foram analisados pelo teste estatístico para rejeição de valores desviantes (Teste Q de Dixon), sendo aceitos ou não [12]. Foram também submetidos à análise de variância dos valores médios das amostras, através do Teste Tukey com nível de significância de 5\% (ANOVA).

\section{RESULTADOS}

Os tempos de crescimento micelial e o tempo total de processo envolvido na produção dos corpos de prova dos biocompósitos estão apresentados na Figura 2.

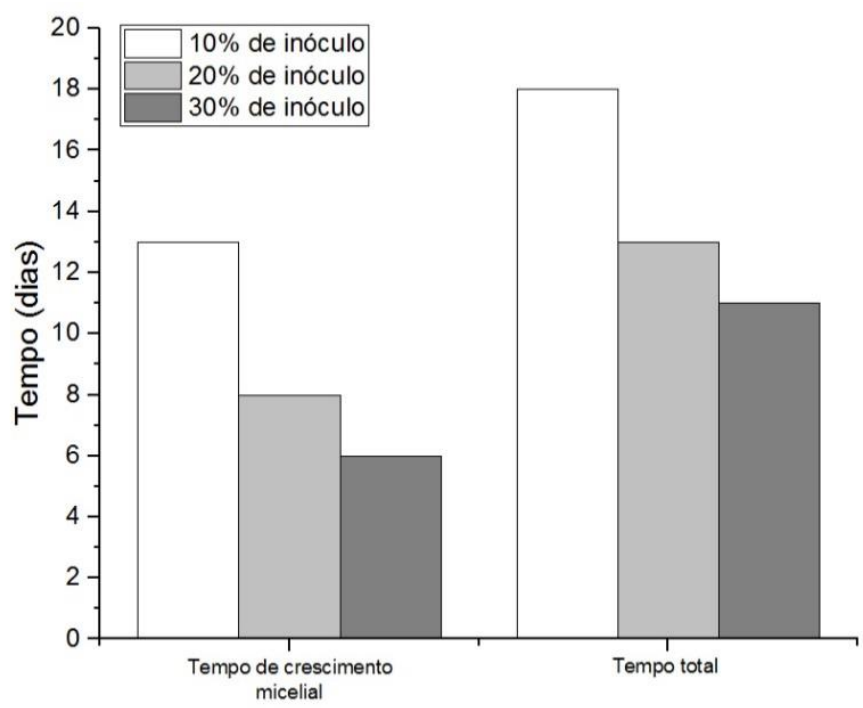

Figura 2: Tempo de crescimento micelial e tempo total do processo de produção dos biocompósitos com 10, 20 ou $30 \%$ de inóculo.

O tempo de crescimento micelial, ou seja, o tempo necessário para a completa colonização dos pacotes, foi 13, 8 e 6 dias para os percentuais de 10, 20 e 30\% de inóculo, respectivamente. Após o resíduo colo- 
nizado pelo micélio fúngico ter sido triturado e distribuído nos moldes, o tempo de recolonização para restabelecimento das hifas foi o mesmo ( 5 dias), para todos os percentuais de inóculo. Assim, o tempo total do processo de produção dos biocompósitos foi de 18, 13 e 11 dias para os percentuais de 10, 20 e 30\% respectivamente.

O tempo total de produção dos corpos de prova não só foi maior para a condição de $10 \%$, como houve, também, uma diferença de tempo maior quando se compara 10 e 20\% (5 dias) com 20 e $30 \%$ ( 2 dias).

No entanto, os corpos de prova devem ser desidratados, para cessar o crescimento fúngico e as temperaturas de secagem de 40 e $60^{\circ} \mathrm{C}$ foram testadas. Na análise das curvas de secagem (Figura 3), observa-se que a fração de inóculo (10, 20 ou 30\%) utilizada na produção dos corpos de prova não influenciou na velocidade de secagem, que pode ser observada, também, na Tabela 1.

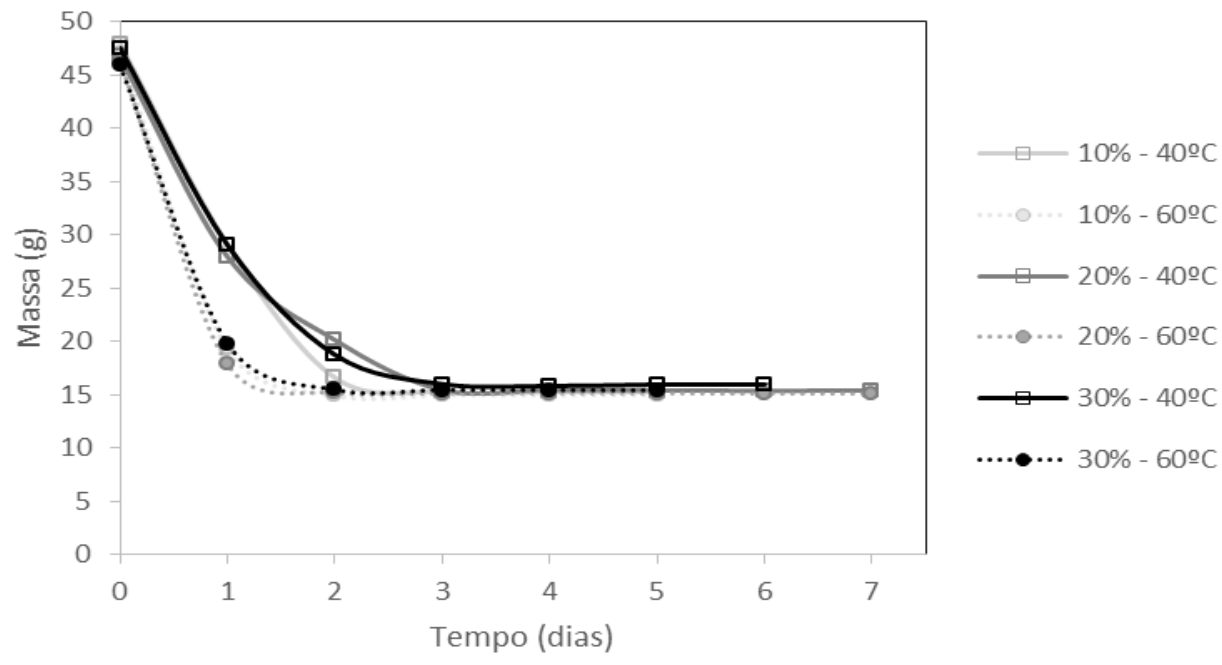

Figura 3: Curvas de secagem, massa (g) x tempo (dias), dos biocompósitos produzidos com 10, 20 ou 30\% de inóculo e secos a 40 e $60^{\circ} \mathrm{C}$.

Ainda, na Tabela 1, observa-se os teores de umidade dos corpos de prova antes da secagem e verificase que, independentemente da fração de inóculo e das temperaturas de secagem utilizadas todos apresentaram teor de umidade em torno de $67 \%$. Em relação a velocidade inicial de secagem verifica-se que os corpos de prova secos a $60^{\circ} \mathrm{C}$ obtiveram maior velocidade inicial de secagem, levando 2 dias para a secagem completa enquanto, os corpos de prova secos a $40^{\circ} \mathrm{C}$ levaram 3 dias, independentemente da fração de inóculo utilizada.

Tabela 1: Valores médios de teor de umidade inicial $\pm \mathrm{dp}$ ( $\mathrm{U}-\%)$, velocidade inicial de secagem $\pm \mathrm{dp}(\mathrm{v}-\mathrm{g} / \mathrm{dia})$ e tempo de secagem (dias) dos corpos de prova produzidos com 10, 20 e $30 \%$ de inóculo secos a 40 e $60^{\circ} \mathrm{C}$. Letras iguais nas colunas, significam médias sem diferença significativa pelo teste de Tukey com nível de confiança de $95 \%$.

\begin{tabular}{c|c|c|c|c}
\hline $\begin{array}{c}\text { Teor de } \\
\text { inóculo (\%) }\end{array}$ & $\begin{array}{c}\text { Temperatura } \\
\text { de secagem } \\
(\mathbf{(} \mathbf{C})\end{array}$ & $\begin{array}{c}\text { Teor de umi- } \\
\text { dade inicial } \\
(\mathbf{U}-\%)\end{array}$ & $\begin{array}{c}\text { Velocidade inicial } \\
\text { de secagem } \\
\mathbf{( v - g / d i a )}\end{array}$ & $\begin{array}{c}\text { Tempo de seca- } \\
\text { gem (dias) }\end{array}$ \\
\hline 10 & 40 & $68,10 \pm 1,49 a$ & $20,36 \pm 3,11 b$ & 3 \\
\hline 10 & 60 & $68,17 \pm 1,28 a$ & $27,72 \pm 1,32 c$ & 3 \\
\hline 20 & 40 & $66,98 \pm 1,58 a$ & $20,10 \pm 3,72 b$ & 2 \\
\hline 30 & 60 & $67,25 \pm 2,84 a$ & $28,46 \pm 2,67 c$ & 3 \\
\hline 30 & 40 & $66,47 \pm 0,85 a$ & $22,32 \pm 1,66 b$ & 2 \\
\hline
\end{tabular}

Analisando-se os tempos de produção dos corpos de prova (Figura 2) e os tempos de secagem (Tabela 1) observa-se que a condição que utilizou $30 \%$ de inóculo e secagem a $60^{\circ} \mathrm{C}$, apresentou um menor tempo total de produção dos corpos de prova (11 dias) e também um menor tempo de secagem ( 2 dias), resultando no menor tempo global de processo (13 dias). 
Quando se observa a Figura 4 verifica-se que os corpos de prova produzidos com 30\% de inóculo e secos a $60^{\circ} \mathrm{C}$ foram os que apresentaram a menor resistência à compressão $(0,057 \mathrm{MPa})$, sem diferença significativa com os corpos de prova produzidos com $10 \%$ e $20 \%$ de inóculo e secos a $40^{\circ} \mathrm{C}$. Os maiores resultados de tensão de compressão foram obtidos para os corpos de prova nas condições de $30 \%$ de inóculo secos a $40^{\circ} \mathrm{C}(0,080 \mathrm{MPa}), 20 \%$ de inóculo secos a $60^{\circ} \mathrm{C}(0,089 \mathrm{MPa})$ e $10 \%$ de inóculo e secos a $60^{\circ} \mathrm{C}(0,094 \mathrm{MPa})$.

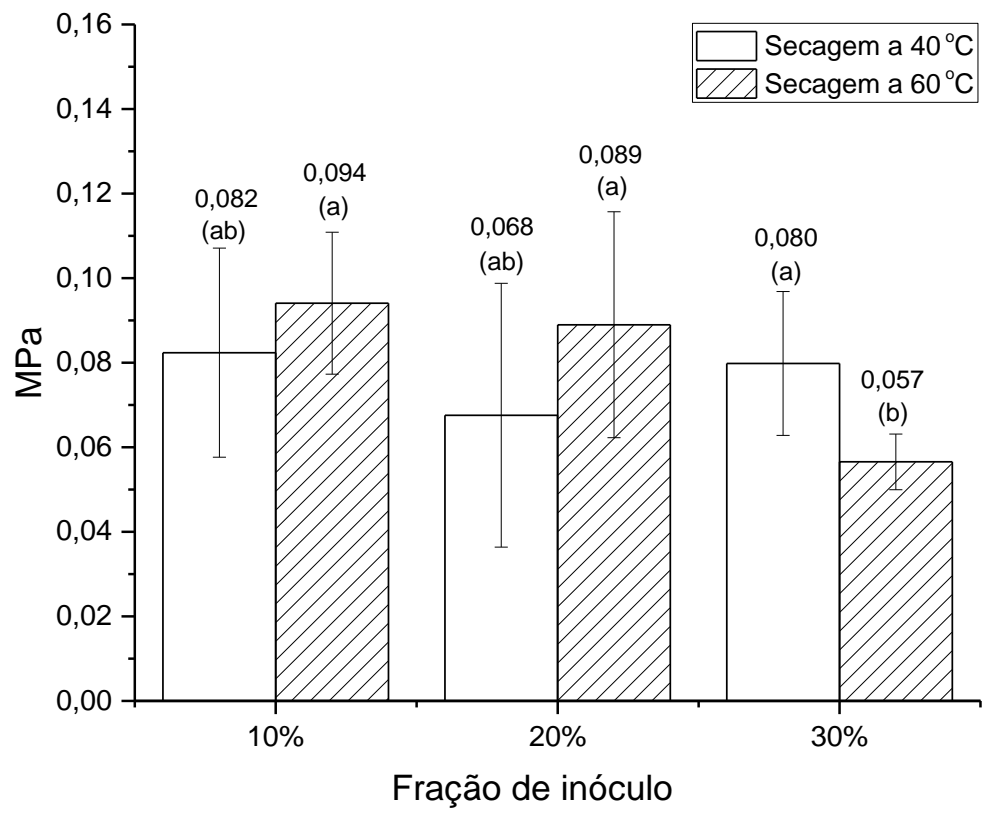

Figura 4: Tensão de compressão para os corpos de prova dos biocompósitos produzidos com 10, 20 ou $30 \%$ de inóculo e secos a 40 e $60^{\circ} \mathrm{C}$. Letras iguais significam valores sem diferença significativa pelo teste de Tukey com nível de significância de $5 \%$.

Para determinar, então, a melhor condição de produção dos biocompósitos, $10 \%$ e $60^{\circ} \mathrm{C}, 20 \%$ e $60^{\circ} \mathrm{C}$ ou $30 \%$ e $40^{\circ} \mathrm{C}$, outros parâmetros envolvidos no processo como absorção de umidade do ar (Figura 5) e absorção de água (Figura 6), foram avaliados.
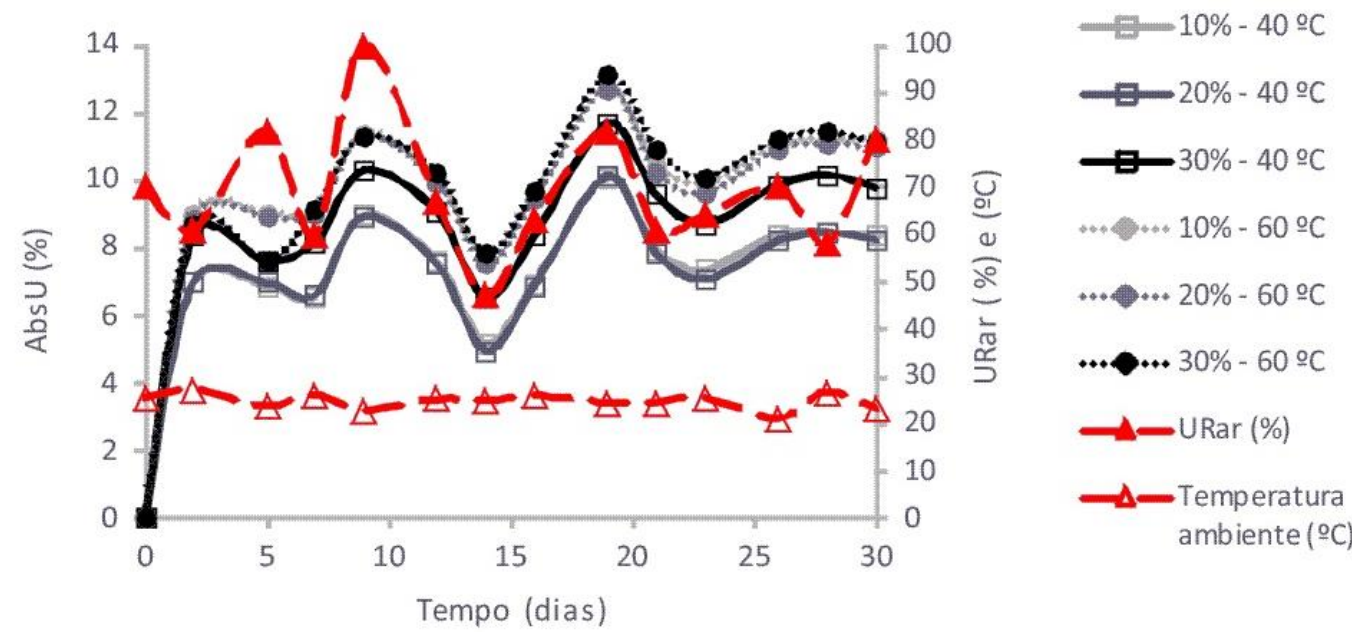

Figura 5: Absorção de umidade do ar $\left(\mathrm{AbsU}_{\mathrm{ar}} \%\right)$ por tempo de exposição (dias) dos biocompósitos produzidos com 10, 20 e $30 \%$ de inóculo e secos a 40 e $60^{\circ} \mathrm{C}$. As linhas segmentadas com símbolo $(\boldsymbol{\Delta})$ e $(\Delta)$ refe- 
rem-se à medida da umidade relativa do ar e a temperatura ambiente, respectivamente, no momento da pesagem.

Na Figura 5 pode-se observar que houve absorção de umidade do ar em todos os corpos de prova testados no período de 30 dias de exposição desses biocompósitos em temperatura ambiente $\left(21-27^{\circ} \mathrm{C}\right)$. Todos os biocompósitos aumentaram o percentual de absorção de umidade quando a umidade relativa do ar era mais elevada e diminuíram quando esta era menor. A umidade relativa do ar variou de $47 \%$ a $100 \%$ e o máximo de absorção de umidade do ar foi de $13,1 \%$ para condição de $30 \%$ de inóculo seco a $60^{\circ} \mathrm{C}$ em 19 dias. Os biocompósitos secos a $60^{\circ} \mathrm{C}$ absorveram maior umidade independentemente da fração de inóculo utilizada. Os que menos absorveram foram os secos a $40^{\circ} \mathrm{C}$ produzidos com 10 e $20 \%$ de inóculo.

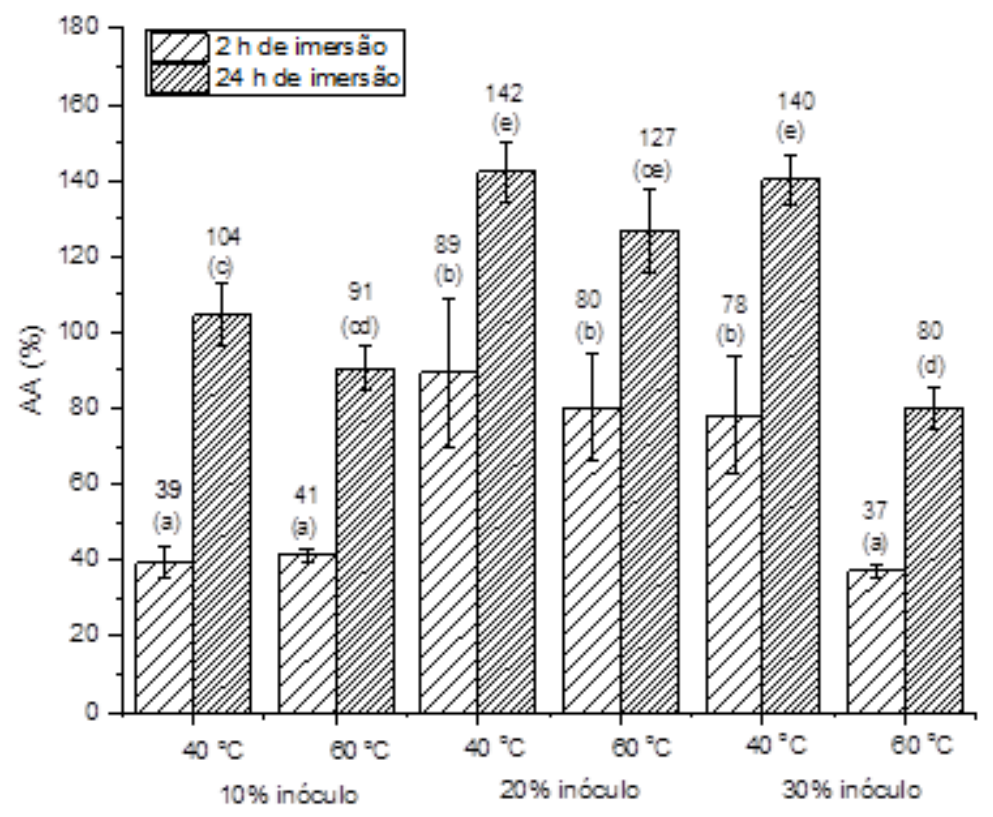

Figura 6: Absorção de água (AA\%) em 2 e 24h de imersão dos biocompósitos produzidos com 10, 20 e $30 \%$ de inóculo no substrato in natura e secos a 40 e $60^{\circ} \mathrm{C}$. Letras iguais significam valores sem diferença significativa pelo teste de Tukey com nível de significância de $5 \%$.

Quando se trata da imersão dos corpos de prova dos biocompósitos em água e tem-se o percentual de absorção de água, observa-se na Figura 6 que em 2 h de absorção os biocompósitos produzidos com 10\% de inóculo secos a 40 ou $60^{\circ} \mathrm{C}$ e os produzidos com $30 \%$ de inóculo e secos a $60^{\circ} \mathrm{C}$ foram os que apresentaram menor absorção de água $(39 \%, 41 \%$ e $37 \%$ respectivamente). Estes mesmos biocompósitos apresentaram, após 24 horas de imersão, uma absorção de água de 104, 91 e 80\%, respectivamente, sem diferença significativa entre si. Os biocompósitos produzidos com $20 \%$ de inóculo secos a 40 ou $60^{\circ} \mathrm{C}$ e os produzidos com $30 \%$ de inóculo secos a $40^{\circ} \mathrm{C}$ apresentaram absorção de água mais elevada em 2 horas com 89,80 e $78 \%$ (sem diferença estatisticamente significativa) e 24 horas com 142, 127 e 140\%, respectivamente (sem diferença estatisticamente significativa).

Com base nos resultados, como já observado na Figura 4, os biocompósitos produzidos com 10 e $20 \%$ de inóculo e secos a $60^{\circ} \mathrm{C}$ ou os produzidos com $30 \%$ de inóculo e secos a $40^{\circ} \mathrm{C}$, foram os que apresentaram maior resistência à compressão. No entanto, a condição de $30 \%$ de inóculo e secagem a $40^{\circ} \mathrm{C}$ levou a uma maior absorção de água (Figura 6). Assim, a condição de $10 \%$ de inóculo e secagem a $60^{\circ} \mathrm{C}$ foi a condição determinada para a produção de biocompósitos utilizando resíduos in natura de erva-mate e guaraná, com absorção de água de $91 \%$ (Figura 6), velocidade de secagem de 27,7 g/dia (Tabela 1), tensão de compressão de 0,094 MPa (Figura 4) e tempo de crescimento micelial de 13 dias (Figura 2). Ainda, os corpos de prova da condição de $10 \%$ de inóculo secos a $60^{\circ} \mathrm{C}$, após os 30 dias de exposição à temperatura ambiente para avaliação da absorção de umidade do ar, foram novamente testados em relação a resistência à compressão (Figura 7). Observa-se que não houve diferença significativa entre os corpos de prova avaliados antes e após à exposição. 


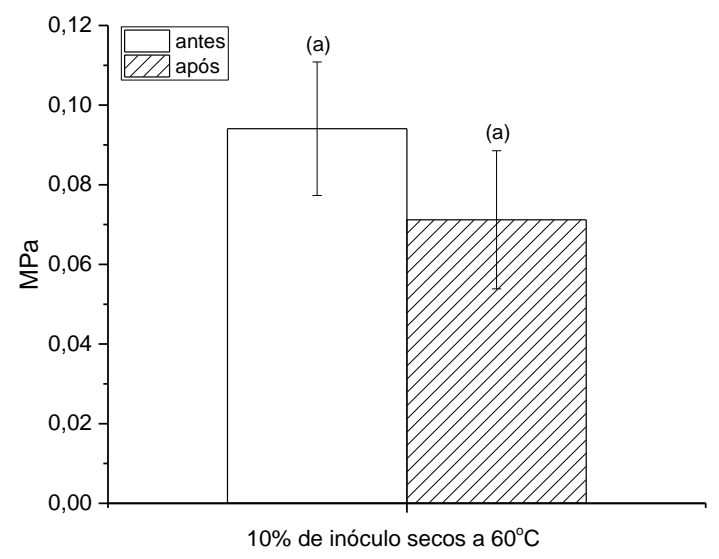

Figura 7: Corpos de prova com $10 \%$ de inóculo secos a $60^{\circ} \mathrm{C}$ antes e após 30 dias de exposição à temperatura ambiente para avaliação da absorção da umidade do ar.

Observa-se na microscopia eletrônica de varredura do biocompósito cultivado com $10 \%$ de inóculo e seco a $60^{\circ} \mathrm{C}$ a presença das hifas miceliais de Pleurotus sajor-caju e as fibras do substrato (Figura 8(a)). Em uma maior ampliação, Figura 8(b), é possível observar as hifas e na Figura 8(c) evidencia-se as hifas recobrindo o substrato.
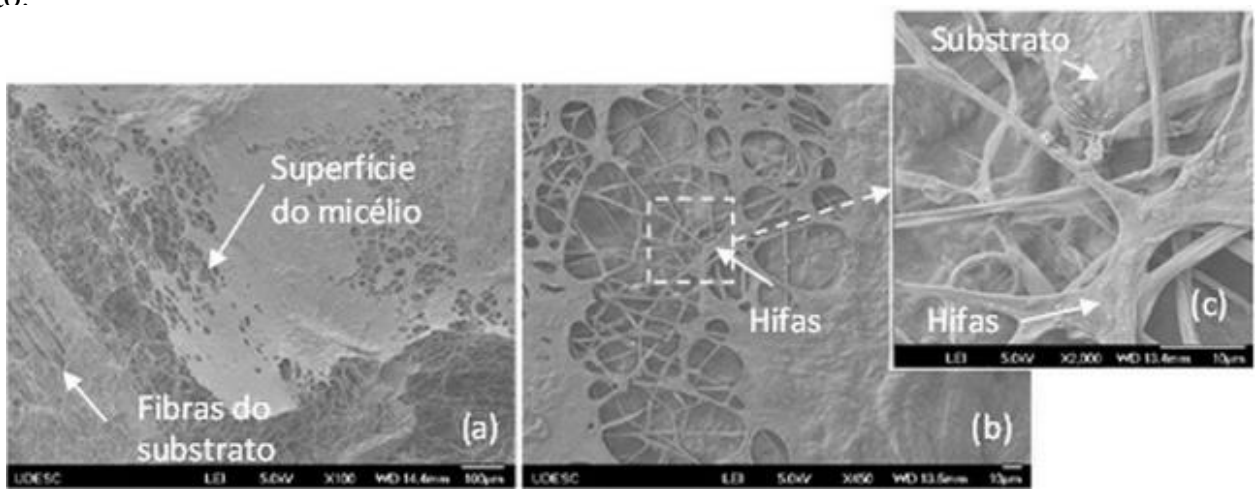

Figura 8: Microscopia eletrônica de varredura do biocompósito com $10 \%$ de inóculo seco a $60^{\circ} \mathrm{C}$ com ampliação de a) 100x; b) 450x e c) 2000x.

O desempenho térmico dos biocompósitos cultivados nos substratos com 10\% de inóculo e secos a $60{ }^{\circ} \mathrm{C}$ pode ser avaliado na Figura 9.

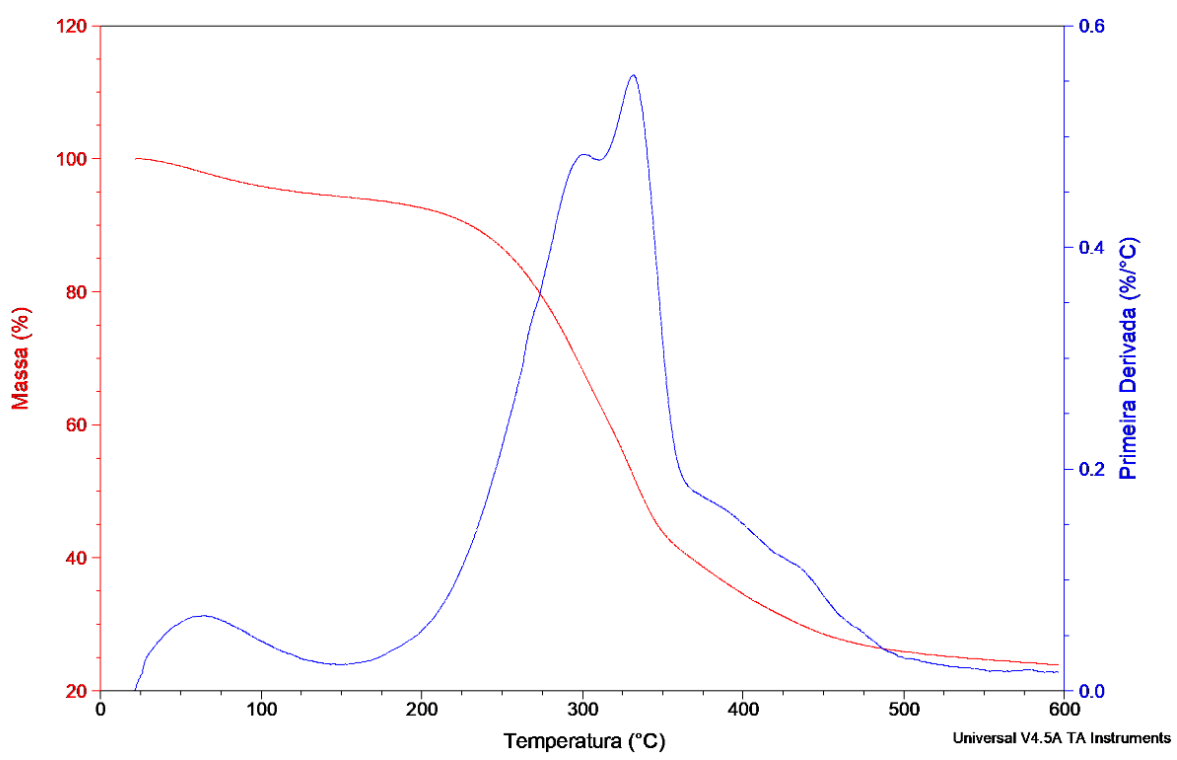


Figura 9: Curvas de TGA e DTG do biocompósito produzido com $10 \%$ de inóculo, seco à $60{ }^{\circ} \mathrm{C}$

Na Tabela 2 estão apresentados os percentuais de perda de massa e as temperaturas de degradação representadas em diferentes estágios do aquecimento do biocompósito.

Pelas curvas de TGA e DTG (Figura 9) e pelos dados da análise termogravimétrica (Tabela 2) é possível observar 3 estágios de perda de massa. $\mathrm{O}$ primeiro estágio de degradação pode ser atribuído à perda de água, que ocorre na faixa de 30 a $150{ }^{\circ} \mathrm{C}$ com um percentual de perda de massa de 5,68\%. O segundo evento térmico causa uma acentuada perda de massa de 54,31\%. Observa-se duas temperaturas máximas $\left(\mathrm{T}_{\max 2}\right)$ associadas ao segundo estágio de degradação, sendo 300 e $332{ }^{\circ} \mathrm{C}$. No terceiro estágio, a perda de massa foi de $16,12 \%$ com 3 temperaturas máximas, 390,437 e $486{ }^{\circ} \mathrm{C}$.

Tabela 2: Dados da análise termogravimétrica do biocompósito produzido com $10 \%$ de inóculo, seco à $60{ }^{\circ} \mathrm{C}$.

\begin{tabular}{cccccc}
\hline $\begin{array}{c}\text { Perda de } \\
\text { massa 1 } \\
(\%)\end{array}$ & $\begin{array}{c}\text { Perda de } \\
\text { massa 2 } \\
(\%)\end{array}$ & $\begin{array}{c}\mathbf{T}_{\operatorname{max2}} \\
\left({ }^{\circ} \mathbf{C}\right)\end{array}$ & $\begin{array}{c}\text { Perda de } \\
\text { massa 3 } \\
(\%)\end{array}$ & $\begin{array}{c}\mathbf{T}_{\operatorname{max3}} \\
\left({ }^{\circ} \mathbf{C}\right)\end{array}$ & $\begin{array}{c}\text { Resíduo } \\
(\%)\end{array}$ \\
\cline { 1 - 5 } 5,68 & 54,31 & 300 & 16,12 & $\frac{390}{4}$ & 23,89 \\
\cline { 3 - 5 } & & 332 & & $\frac{437}{486}$ \\
\hline
\end{tabular}

\section{DISCUSSÃO}

A discussão com a literatura foi realizada para o biocompósito definido na melhor condição que foi de $10 \%$ de inóculo e secagem a $60^{\circ} \mathrm{C}$. Em termos do tempo de crescimento micelial, 13 dias (Figura 2), este foi similar ao trabalho de PEDRI [13] que foi de 12 dias para a produção de biocompósitos a partir de fibras de pupunha com 1/6 de placa de Petri com meio BDA de inóculo sólido de Lentinula edodes. Já, tratando-se do teor de umidade inicial obtido neste trabalho, 68,17\%, verifica-se que foi superior ao biocompósito obtido por PEDRI [13] que foi de 59,7\%, apesar de materiais fibrosos absorverem umidade mais facilmente [14].

Na Tabela 3 os valores de resistência à compressão (tensão de compressão em MPa) foram comparados a outros materiais biocompósitos similares a este, encontrados na literatura, e com EPS (poliestireno expandido - isopor) [15], uma vez que este biocompósito tem potencial a tornar-se um substituto deste material.

Tabela 3: Tensão de compressão para diferentes materiais constituídos por material lignocelulósico e micélio fúngico e EPS $\left(10\right.$ a $\left.18 \mathrm{~kg} / \mathrm{m}^{3}\right)$.

\begin{tabular}{c|c|c}
\hline Material/biocompósito & $\begin{array}{c}\text { Tensão de } \\
\text { Compressão } \\
\text { (MPa) }\end{array}$ & Referências \\
\hline Erva-mate e guaraná e Pleurotus sajor-caju* & $0,094 \pm 0,017$ & Figura 4 \\
\hline Polpa de serragem de bétula e Irpex lacteus & $0,35-0,47$ & YANG et al. [3] \\
\hline Algodão e fibra de tecido** & 1,18 & ZIEGLER et al. [4] \\
\hline Fibra de pupunha e Lentinula edodes & $0,21-0,25$ & PEDRI [13] \\
\hline Carvalho vermelho e Ganoderma lucidum & 0,49 & TRAVAGLINI et al. [16] \\
\hline Algodão e Ganoderma lucidum & 0,072 & HOLT et al. [2] \\
\hline Poliestireno expandido $\left(10 \mathrm{~kg} / \mathrm{m}^{3}\right)^{*}$ & 0,035 & NBR 11752 [15] \\
\hline Poliestireno expandido $\left(12 \mathrm{~kg} / \mathrm{m}^{3}\right)^{*}$ & 0,035 & NBR 11752 [15] \\
\hline Poliestireno expandido $\left(15 \mathrm{~kg} / \mathrm{m}^{3}\right)^{*}$ & 0,069 & NBR 11752 [15] \\
\hline Poliestireno expandido $\left(18 \mathrm{~kg} / \mathrm{m}^{3}\right)^{*}$ & 0,090 & NBR 11752 [15] \\
\hline
\end{tabular}

*Tensão de compressão com deformação de $10 \%$, **Espécie fúngica não mencionada. 
O biocompósito fúngico constituído com resíduos de erva-mate e guaraná, utilizando $10 \%$ de inóculo e $60^{\circ} \mathrm{C}$ como temperatura de secagem, produzido neste trabalho, obteve valor de resistência à compressão superior ao valor encontrado por HOLT et al. [2], (0,072 MPa) utilizando resíduo de algodão. Porém, em comparação com os outros biocompósitos similares (Tabela 3) apresentou valores menores de resistência à compressão.

O maior valor de resistência à compressão (1,18 MPa) foi encontrado por ZIEGLER et al. [4], ao adicionar fibra de tecido ao resíduo de algodão. YANG et al. [3], também afirma que a adição de fibras naturais ao substrato utilizado (polpa de serragem de bétula) foi capaz de aumentar a resistência à compressão do biocompósito produzido. Segundo YANG et al. [3], isso ocorre, pois, as fibras têm a capacidade de aumentar a rigidez e minimizar possíveis fissuras na superfície do biocompósito durante o teste de resistência à compressão.

Segundo ZIEGLER et al. [4], o tipo de resíduo (ou até mesmo a mistura entre dois ou mais resíduos) e o fungo utilizado na produção do biocompósito, podem alterar diversas propriedades mecânicas do material, incluindo a resistência à compressão.

Em relação ao tipo de fungo utilizado, JONES et al. [17], afirma que, a espécie Trametes versicolor tem maior resistência à compressão do que Pleurotus ostreatus (mesmo gênero do fungo utilizado neste trabalho), até quando cultivado no mesmo substrato. Segundo o autor, isso ocorre devido ao tipo de hifas (monomíticas para Pleurotus e trimíticas para Trametes) apresentada por cada espécie.

Para aprimorar as propriedades do material, deve-se controlar o tipo de resíduo utilizado, o tipo de fungo e a suplementação de aditivos naturais para melhorar a interação entre a interface fungo e substrato [17]. No entanto, a resistência à compressão apresentada para o biocompósito definido neste trabalho $(0,094 \pm 0,017 \mathrm{MPa})$ é superior a resistência à compressão do poliestireno expandido de até $18 \mathrm{~kg} / \mathrm{m}^{3}$. Desta forma, o biocompósito em estudo tem potencial de aplicação em diferentes setores da indústria. A resistência à compressão é uma propriedade importante quando se trata de materiais que serão utilizados para embalagem, pois estas estão sujeitas a sofrerem esforços compressivos durante seu transporte [17]. Uma das principais aplicações do poliestireno expandido é confecção de embalagens, sendo esta, uma possível aplicação para o biocompósito produzido neste trabalho.

Em termos de absorção de umidade do ar, na Figura 5 observa-se que os biocompósitos produzidos com $10 \%$ de inóculo e secos a $60^{\circ} \mathrm{C}$ absorveram em torno de $10 \%$ de umidade do ar em 30 dias de experimentação. Apesar disso, estes biocompósitos não mostraram diferença significativa em termos de resistência à compressão quando comparados aos biocompósitos recém obtidos (Figura 7), aumentando sua possibilidade de aplicação em embalagens. Ainda que, estes corpos de prova apresentaram absorção de umidade do ar, não foi observada contaminação por exemplo, por fungos do gênero Trichoderma, contaminação comum em substratos fúngicos. Estes fungos apresentam micélio branco com esporulação escura, facilmente detectada a olho nú [18].

Os valores de absorção de água (41\% em 2 h e $126 \%$ em 24 h de imersão) apresentados na Figura 6, são menores que os encontrados por PEDRI [13], ao produzir biocompósitos com fibra de pupunha e Lentinula edodes que obteve um valor de absorção de água de $374,24 \%$ em $2 \mathrm{~h}$ de imersão e de $378,43 \%$ em $24 \mathrm{~h}$ de imersão. A autora obteve um aumento em torno de apenas $4 \%$ de absorção de água entre 2 e $24 \mathrm{~h}$ de imersão, ou seja, em apenas 2 horas o biocompósito praticamente atingiu a saturação. No presente trabalho, entretanto, além do biocompósito apresentar menor absorção de água, observou-se um aumento de 50\% entre 2 e 24 horas de imersão, mostrando que o biocompósito cultivado no substrato erva-mate e guaraná absorve água mais lentamente do que os produzidos por PEDRI [13]. Cabe lembrar que as fibras naturais tendem a aumentar a absorção de água induzindo uma perda das propriedades mecânicas [14]. Segundo MA et al. [19], a sensibilidade à água é um critério importante para muitas aplicações práticas de compósitos, determinando assim o seu desempenho em condições adversas. Ou seja, quanto menor o teor de água absorvido, melhor o desempenho do material para uma possível aplicação em que o material se encontre em contato com água [20].

Em relação a análise morfológica do micélio fúngico nos corpos de prova cultivados com 10\% de inóculo e secos a $60^{\circ} \mathrm{C}$ (Figura 8c), observa-se que as hifas miceliais aparentam estar pouco aderidas ao substrato. No entanto, PESSONI et al. [21] evidenciaram alterações morfológicas no micélio do fungo Penicillium janczewskii induzidas pela fonte de carbono, onde hifas cultivadas em meio contendo frutose revelaram-se significativamente mais finas quando comparadas com as cultivadas em sacarose e glicose. PEDRI [13] avaliou a micrografia de um biocompósito de fibra de pupunha e Lentinula edodes e constatou que a estrutura do micélio atuou como microfibrilas similares a celulose, melhorando as propriedades mecânicas do material estudado. 
No que se refere à análise termogravimétrica (Tabela 2), pôde-se observar uma perda de massa de $54,31 \%$ no segundo evento térmico com temperaturas máximas de degradação de 300 e $332^{\circ} \mathrm{C}$. ALEMDAR e SAIN [22] afirmam que temperaturas maiores de início de degradação indicam maior estabilidade térmica do material. HANEEF et al. [23] relataram a temperatura de degradação térmica de biocompósitos utilizando os fungos Ganoderma. lucidum e Pleurotus ostreatus na faixa de 225 a $300{ }^{\circ} \mathrm{C}$ evidenciando estas temperaturas como sendo elevadas temperaturas de degradação, comprovando que esses biocompósitos são termicamente estáveis, expandindo seus campos de aplicação. Já, NUNES [24] obteve para EPS puro apenas um estágio de degradação térmica iniciando em $355^{\circ} \mathrm{C}$ com temperatura final de $440{ }^{\circ} \mathrm{C}$.

O resíduo obtido ao final do ensaio foi de 23,89\%. HANEEF et al. [23] obtiveram resultados similares a este trabalho com teor de resíduos entre 15 e $25 \%$ com biocompósitos de G. lucidum e $P$. ostreatus na temperatura de $600{ }^{\circ} \mathrm{C}$. JONES et al. [17], em biocompósito de Trametes versicolor, obtiveram $25 \%$ de resíduo formado em $500{ }^{\circ} \mathrm{C}$ e concluíram que em temperaturas mais elevadas que essa última há quedas insignificantes de perda de massa para materiais baseados em micélio.

\section{CONCLUSÕES}

O presente trabalho foi desenvolvido visando ampliar o aproveitamento e agregar valor aos resíduos produzidos em maior quantidade por uma indústria de aromas (erva-mate e guaraná). Para tanto, a mistura entre tais resíduos foi utilizada juntamente com uma espécie fúngica (Pleurotus sajor-caju), com o objetivo de reduzir a quantidade destes resíduos depositados no meio ambiente, por meio da sua transformação em biocompósito fúngico.

A utilização destes resíduos demonstrou potencial para a produção de um biocompósito a partir de ervamate e guaraná $(1: 1)$ com $10 \%$ de inóculo e secagem a $60^{\circ} \mathrm{C}$, pois apresentou maior resistência à compressão (0,094 MPa), menor absorção de água (91\%), maior velocidade de secagem (27,7 g/dia) e boa estabilidade térmica $\left(300^{\circ} \mathrm{C}\right)$. Estes biocompósitos apresentaram potencial para serem utilizados como material substituinte ao EPS (poliestireno expandido), pois apresentaram resultados superiores de resistência à compressão.

Evidencia-se que os biocompósitos de erva-mate, guaraná e P. sajor-caju são materiais seguros devido ao fato de serem constituídos por biomoléculas associadas a carboidratos (celulose e quitina) e assim, ao sofrerem degradação térmica liberam substâncias voláteis não tóxicas e não combustíveis. Em contraste, o EPS libera gases voláteis altamente inflamáveis e tóxicos durante a combustão, o que aumenta significativamente o risco de incêndio associado.

\section{AGRADECIMENTOS}

À Universidade da Região de Joinville - UNIVILLE, pela disponibilização dos laboratórios de Biotecnologia II e de Análises Mecânicas (CAMEGI) no qual foi realizada a parte experimental deste trabalho e à CAPES pela concessão da bolsa de estudos ao longo do curso de mestrado.

\section{BIBLIOGRAFIA}

[1] BAYER, E., MCLNTYRE, G., SWERSEY, B.L., Method for producing grown materials and products made thereby. In: World Intellectual Property Organization, number WO 2008/073489 A2. https://patents.justia.com/inventor/eben-bayer?page=2, 2008. Acessado em setembro de 2017.

[2] HOLT, G.A., MCINTYRE, G., FLAGG, D., et al., Fungal mycelium and cotton plant materials in the manufacture of biodegradable molded packing material: Evaluation Study of Select Blends of Cotton Byproducts. Journal of Biobased Materials and Bioenergy, v. 6, n. 4, pp. 431-439, Nov. 2012.

[3] YANG, Z., ZHANG, F., STILL, B., et al.,Physical and mechanical properties of fungal mycelium-based biofoam. Journal of Material in Civil Engineering, v. 27, pp. 1-9, Mar. 2017.

[4] ZIEGLER, A.R., BAJWA, S.G., HOLT, G.A., et al.,Evaluation of physico-mechanical properties of mycelium reinforced Green biocomposites made from cellulosic fibers. American Society of Agricultural and Biological Engineers, v. 32, n. 6, pp. 931-938, Dec. 2016.

[5] ECOVATIVE. About. Disponível em:< https://ecovativedesign.com/about>. Acesso em 20 out. 2017.

[6] CHANG, S.T., MILES, P.G., Mushrooms: cultivation, nutritional value, medicinal effect and environmental impact, 2 ed., New York, CRC Press, 2004.

[7] FURLAN, S.A., VIRMOND, L.J., MIERS, D.A., et al.,Mushrooms strains able to grow at high temperatures and low pH values. World Journal of Microbiology and Biotechnology, v. 13, pp. 689-692, Nov. 1997. 
[8] BONATTI, M., KARNOPP, P., SOARES, H.M., et al.,Evaluation of Pleurotus ostreatus and Pleurotus sajor-caju nutritional characteristics when cultivated in different lignocellulosic wastes. Food Chemistry, v. 88, pp. 425-428, Dec. 2004.

[9] MADAN, M., VASUDEVAN, P., SHARMA, S., Cultivation of Pleurotus sajor-caju on different agrowastes. Biological Wastes, v. 22, n.4, pp. 241-250, Dec. 1987.

[10] ABNT (2016), NBR 8082: Espuma rígida de poliuretano para fins de isolação térmica - Determinação da resistência a compressão. Rio de Janeiro, Associação Brasileira de Normas Técnicas.

[11] ASTM INTERNATIONAL (1998), D570-95: Standard Test Method for Water Absorption of Plastics. New York, American Society for Testing and Materials.

[12] RORABACHER, D.B., Statistical treatment for rejection of deviant values: critical values of Dixon's "Q" parameter and related subrange rations at the 95\% confidence level. Analytical Chemistry, v. 63, n. 2 , pp.139-146, Jan. 1991.

[13] PEDRI, Z.C., Uso de biomassa lignocelulósica e Lentinula edodes (Berk.) Pegler para desenvolvimento de um biocompósito. Dissertação (Mestrado em Engenharia Ambiental), FURB, Blumenau, SC, Brasil, 2014.

[14] DUFRESNE, A., BELGASEN, N.M., Cellulose-reinforced composites: from micro-to nanoscale. Polímeros, v. 23, n. 3, p. 227-286, 2013.

[15] ABNT (2016), NBR 11752: Materiais celulares de poliestireno para isolamento térmico na construção civil e refrigeração industrial - Especificação. Rio de Janeiro, Associação Brasileira de Normas Técnicas.

[16] TRAVAGLINI, S., NOBLE, J., ROSS, P.G., et al., "Mycology matrix composites proceedings", In: American Society for Composites - Twenty-Eighth Technical Conference, State College, PA, US, 517-535, Set, 2013.

[17] JONES, M.; HUYNH, T.; DEKIWADIA, C.; DAVER, F.; JOHN, S. Mycelium composites: A review of engineering characteristics and growth kinetics. Journal of Bionanoscience, v. 11, n. 4, pp. 241-257, Ago. 2017.

[18] CHA, J.S. Pest and Disease Management. In: Mushroom grower's handbook - Oyster mushroom cultivation, (Mushroom Ed.), Seoul, Mushword-Heineart Inc, pp. 172-186, 2004.

[19] MA, X., CHANG, P.R., YU, J., et al.,Properties of biodegradable citric acid-modified granular starch/thermoplastic pea starch composites. Carbohydrate Polymers, v. 75, n. 1, pp. 1-8, Jan. 2009.

[20] CASTRO, D.O., FROLLINI, E., MARINI, J., et al.,Preparação e caracterização de biocompósitos baseados em fibra de curauá, biopolietileno de alta densidade (BPEAD) e polibutadieno líquido hidroxilado (PBHL). Polímeros, v. 23, n. 1, pp. 65-73, 2013.

[21] PESSONI, R.A.B.; TERSAROTTO, C.C.; MATEUS, C.A.P.; et al.,Fructose affecting morphology and inducing $\beta$-fructofuranosidases in Penicillium janczewskii. SpringerPlus, v. 4, pp. 1-11, Set. 2015.

[22] ALEMDAR, A., SAIN, M. Biocomposites from wheat straw nanofibers: Morphology, thermal and mechanical properties. Composites Science and Technology, v. 68, pp. 557-565, 2008.

[23] HANEEF, M., CESERACCIU, L., CANALE, C., et al., Advanced materials from fungal mycelium: fabrication and tuning of physical properties. Scientific Reports, v. 7, pp. 1-11, 2017.

[24] NUNES, V.D.B. Caracterização do compósito formado por poliestireno expandido (EPS) e celulose microcristalina: Impermeabilizante de superfícies. Dissertação (Mestrado em Ciência dos Materiais), UFPI, Teresina, PI, Brasil, 2016.

\section{ORCID}

Maria Isabel Rocha

Sara Benkendorf

Regina Maria Miranda Gern

Josiane Costa Riani

Elisabeth Wisbeck https://orcid.org/0000-0003-2770-5353

https://orcid.org/0000-0003-0038-7826

https://orcid.org/0000-0002-6492-4689

https://orcid.org/0000-0002-3575-3083

https://orcid.org/0000-0002-5801-7863 